\title{
POLITICA DE PLANEAMIENTO EN LOS MUNICIPIOS RURALES DE SAO PAULO
}

711 (81 São Paulo)

por

\section{A. Delorenzo Neto}

Director de la Escuela de Sociología y Política de Sāo Paulo

En Brasil la población actual es de aproximadamente $105 \mathrm{mi}-$ llones de habitantes. Considerando la hipótesis de expansión con una tasa del 2,8 por 100 al año, la población total alcanzaría 123 millones en el año 1980, de los cuales, aproximadamente, 78 millones en el área urbana y 45 millones en la zona rural. Por lo tanto, es evidente la tendencia de concentración urbana y metropolización. En el Estado de São Paulo, el más populoso de la Federación, con 20 millones de habitantes, cerca de 11 millones se encuentran en la Región metropolitana.

De esta forma son posibles medidas que impidan la desruralización, permitiendo un mejor y mayor progreso en las áreas rurales, evitándose el éxodo para los grandes centros, especialmente la acumulación de la emigración interna, que tanto contribuye a la marginación.

Una de las vías eficaces para esos reequilibrios estructurales se encuentra en los métodos de planificación y en la concepción sociológica de MANN heIM, que asegura la posibilidad de una dirección consciente de la sociedad. Esas medidas, a nuestro criterio, no deben ser tomadas solamente a nivel federal, como la legislación relativa al trabajador rural, especialmente la Ley 5.889/1973. 
Un extenso campo de planificación corresponde a la iniciativa de los Gobiernos municipales, de acuerdo con los principios de autonomía consagrados en las Constituciones federales, y en las Constituciones de los Estados (1).

En la Constitución del Estado de São Paulo, en su artículo 120, encontramos esta disposición, bastante innovadora en su alcance metodológico:

«El Estado deberá:

I. Promover el desarrollo económico y social mediante un planeamiento, estímulo a la planificación municipal e incentivo a la iniciativa particular de interés para la comunidad.

II. Establecer directrices para la integración de los Planes municipales y regionales en el planeamiento del Estado y nacional, promulgando normas técnicas convenientes".

A su vez, la Ley Orgánica de los Municipios del Estado de São Paulo del 31 de diciembre de 1969 establece en su artículo 54 esta norma bastante explícita: "Los Municipios iniciarán el proceso de planeamiento, elaborando el Plan Director de desarrollo integral en el cual considerará, en conjunto, el aspecto físico, económico, social y administrativo".

Estos elementos jurídicos son suficientes para posibilitar la investigación sociológica indispensable como soporte al planeamiento de los Municipios, especialmente los de las áreas rurales, con el fin de mejor armonizarlosmon las necesidades de la sociedad global.

\section{II}

Es necesario también revisar los propios esquemas de la estruc. tura político-administrativa, especialmente considerando los grandes países de tipo federal como Brasil La división clásica de la Federación en tres niveles: Unión Federal, Estados miembros y Municipios, nos parece insuficiente para dar un tratamiento adecuado a las comunidades de base de naturaleza rural.

Aquí la ecología nos orienta con sus elementos propodénticos. La ecología completa a la sociología en el sentido de permitirle

(1) Leer los artículos 15 de la Constitución federal y 120 de la Constitución del Estado de São Paulo. 
el conocimiento de la correlación de los fenómenos sociales con la naturaleza. Las relaciones socio-especiales se configuran, concretamente, en un orden ecológico en que se destaca la comunidad biótico-organización funcional y estructural de la vida, que resulta de la mutua relación e interdependencia de las especies dentro de un habitat común. Cuatro modelos pueden ser identificados por los ecologistas, objetivamente, en la diferenciación espacial de la especie humana, ellos son:

1. Modelos mundiales.

2. Naciones o Estados.

3. Regiones.

4. Comunidades funcionales.

La organización ecológica nos permite, a través de sus modelos, evaluar la manera por la cual la competición distribuye los seres humanos e instituciones en unidades funcionales. Solamente teniendo en cuenta este moderno concepto es que podemos comprender la difícil problemática de la integración territorial de cara a la diferenciación o aislamiento de las áreas urbanas y rurales.

Las comunidades funcionales, como unidades político-económicas elementales, serían mejor configuradas en un cuadro regional sensatamente definido a través de la investigación. Corresponden en la terminología de algunos sociólogos, como LEBRET, a las zonas homogéneas. La realidad más favorable para incrementar el desarrollo es la realidad regional, y puede ser identificada a través de las zonas homogéneas. Aunque haya divergencias en cuanto al propio concepto de Región, en el caso de Brasil es posible distinguirla como espacio intermedio entre los Municipios, en general demasiado pequeños, y el Estado, demasiado grande.

La adopción del criterio regional podrá corregir las desigualdades del tamaño del territorio y de la rigidez de la división políticoadministrativa, que impide casi siempre un aprovechamiento racional del espacio, dificultando el movimiento de recursos para el desarrollo.

La noción de zona homogénea, en cuanto unidad elemental, incluye todas las subzonas de más homogeneidad y debe ser aplicada cuidadosamente por niveles de criterios. De tal forma que los factores «suelo-clima-relieve» determinarían una primera homogeneidad; los factores «utilización del suelo-irrigación» determinan una segunda, y el factor que reside en el «tipo de las explotaciones» 
una tercera, etc. Los criterios o condiciones de contacto global preliminar pueden variar de Región a Región. Esas zonas homogéneas deben constituir, por tanto, en cualquier tipo de planeamiento las unidades tácticas preferenciales del desarrollo. No obstante, no se debe subestimar la gran importancia de las zonas de polarización alrededor de un centro que constituye la unidad de vida colectiva completa (pequeña Región); o área metropolitana (gran Región). Las Regiones son generalmente compuestas de zonas homogéneas $o$ de fracciones de zonas homogéneas, diferenciadas entre aquellas en las que los centros polarizadores operan las uniones. Los dos modelos de unidad - la pequeña Región y la gran Regiónposeen también un importante papel táctico, debiendo disponer de equipos que controlen y coordinen el trabajo de los equipos de las zonas homogéneas. Los análisis se deben, por tanto, ceñir a estas dos perspectivas y permitir una primera elaboración estadística y auxiliar a la planificación, teniendo en cuenta el desarrollo armónico. La síntesis global será realizada en el plano de la Nación. La sistematización del análisis intenta alcanzar estos objetivos:

1. Comparar las zonas homogéneas entre sí.

2. Reconstruir una estructura de la Región a partir de los datos de las zonas homogéneas.

3. Elaborar la estructura nacional por la integración de los datos de la Región.

4. Deducir para las diversas etapas las investigaciones preferenciales.

Estamos, como se demuestra, delante de una perspectiva estructural partiendo de la base para alcanzar la cumbre, diferenciándose del mero estudio estadístico o de coyuntura, que recurre inicialmente a datos globales. Es notable en esta teoría que las etapas de investigación tengan su existencia propia; en estas condiciones es necesario distinguir el análisis preliminar que da a las autoridades del país las perspectivas generales del plan indicativo del desarrollo y los análisis subsecuentes que deben, por zonas homogéneas y por Regiones, preparar los Planes de Desarrollo de los Estados. Los Planes deben ser articulados entre los diferentes niveles de la Federación: Unión Federal, Estados miembros y Municipios. Le incumbirá a la planificación federal las tareas de coordinación y la de ejecución, y la estrategia de las peculiaridades 
regionales y locales serán preferiblemente atribuidas a las Administraciones estatales y municipales.

\section{III}

La regionalización se vuelve absolutamente indispensable para la realización del propio Plan nacional. Muchos Planes gubernamentales, como la importante Planificación de Senegal (1961-1964) técnicamente perfecta, fracasó por la carencia de sectores regionales, sea desde un punto de vista económico, sea del punto de vista de la estructura administrativa.

Las Regiones se debilitan por el esfuerzo que se da a los poderes centrales del Estado. Si hay una polarización de las relaciones territoriales políticas y económicas, ella se realiza casi siempre en beneficio de la "unidad», debilitando las Regiones y las ciudades, que pueden volverse decadentes. Asistimos a una tendencia a la "desregionalización», y este fenómeno tiene alcanzado indiferentemente Estados unitarios y Estados federales, tales como Francia y los Estados Unidos. Los procesos de unificación política practicados por todas partes tiene perjudicados los intereses regionales porque desprecian el valor de las realidades ecológicas en su profundo significado geo-económico. Por lo tanto, cualquier esfuerzo que se haga en el sentido de mejorar la estructura urbana o rural no será eficaz, a no ser que se base en una redefinición de las zonas de asociación territorial en consecuencia con los hechos geográficos, económicos y sociales. Por eso no se debe contrariar la diversidad regional cuando el propio ambiente ecológico lo impone en un país. Oponerse a ese proceso natural sería concebir una falsa uniformidad en perjuicio de una posible unidad cultural resultante de una infraestructura común interregional. En Brasil, el sociológo Gilberte FREYRE preconiza una vigorosa política integrativa de los valores $\mathrm{y}$ actividades urbanas, de actividades $\mathrm{y}$ valores industriales, de valores y actividades rurales; solamente ella podrá corregir las disparidades en busca del equilibrio rural urbano.

Teórica y prácticamente, el problema presenta dificultades. La primera de ellas es la delimitación de las Regiones. Los factores que ahí intervienen son complejos y varían de acuerdo con las condiciones típicas de cada lugar, siendo tantas veces necesario ultrapasar límites jurisdiccionales, sean municipales, estatales o fede- 
rales. En oposición a la Región meramente geográfica, el área indicada para el planeamiento regional debe presentar cierta flexibilidad en sus límites que le permita adaptarse a la posible extensión de un centro determinado al mismo tiempo que homogeneidad en sus características propias. La Región debe aún ser suficientemente grande para que pueda ofrecer el máximo de acceso al bienestar colectivo de acuerdo con la realidad económica, y suficientemente pequeña con el fin de que la colectividad pueda de alguna forma participar de los asuntos de Administración local. Esas exigencias llevan a la comprensión de la Región como una unidad social en el sentido de un equilibrio dinámico entre sus distintas partes. Por lo tanto, el planeamiento regional con el fin de objetivarse correctamente debe abarcar todos los factores que condicionan el funcionamiento integral de la Región.

\section{IV}

En esa perspectiva, debemos situar dentro de la Región las comunidades funcionales. Si conseguimos determinarlas, un paso al frente será dado en la obtención de un modelo de organización espacial y, especialmente, teniendo en cuenta la insuficiencia de la planificación municipal en sí misma y de la expansión de las áreas locales. Todos los criterios hasta ahora utilizados -en la práctica- para la definición de los espacios, geográfico, jurídico o económico son demasiado restringidos. Es imprescindible reconocer la complejidad del contenido de las áreas de cara a una dinámica incontrastable. Sólo una interpretación sociológica, esto es, considerando la comunidad como unidad-base funcional, es lo que podrá dilucidar la problemática de la Región en términos de planeamiento. La jerarquía funcional de la organización territorial no debe parar en el Municipio o en el Distrito. Es preciso ordenar funcionalmente más allá de la rigidez de la división política, investigando los problemas comunes de las zonas homogéneas. Una nueva unidad operacional provendrá del reconocimiento de la comunidad funcional agrupando o integrando hasta unidades políticas diferentes (Municipios o Distritos).

De esta forma podemos reorientar la planificación municipal, sobre todo en los Estados federales que posibilitan amplia autonomía a los Municipios. El reagrupamiento de los Municipios por 
Regiones, o sea, la regionalización de las actividades municipales, respetará los valores típicos, los valores profundos de la cultura local que acaban amenazados o deprimidos por la sociedad industrial o por la excesiva concentración del poder político y de la burocracia.

La preservación de los Municipios rurales, con gobiernos y administración propios, se impone como medida de precaución contra la excesiva urbanización especialmente en los países subdesarrollados, tan sobrecargados por el ritmo de las emigraciones. Asegurada la iniciativa de las colectividades de base con mecanismos suficientes de descentralización y mayores recursos financieros, serán más eficaces las corrientes de innovación a través de la comunicación intersectorial, eliminándose la constante dependencia entre el centro y la periferia (2), y así los Distritos rurales pasarían a operar efectivamente en la reducción de la distancia social con nuevos índices de desarrollo político y económico.

(2) En relación al Estado de São Paulo, destacamos la iniciativa del Gobierno del Estado. creando el 12 de diciembre de 1970 por el Decreto núm. 52.576 las Regiones administrativas en número de 11, cada una de ellas con Oficina Técnica de Planeamiento, con el objetivo de orientar la política de desarrollo del Estado, actualmente con 20 millones de habitantes. 


\section{BIBLIOGRAFIA}

A. Delorenzo Neto: De la integración regional, São Paulo, Librería Dos Ciudades, 1974.

Costa Pinto: Sociología y desarrollo, Río de Janeiro, Editorial Civilización Brasileira 1973.

Gilberto FreYre: Brasis-Brasil-Brasilia, Río de Janeiro, Editorial Gráfica Récord, 1968.

Karl Mannheim: Libertad, poder y planificación democrática, São Paulo, Editorial Mestre Jou, 1972.

L. J. LeBRET: Dinámica concreta del desarrollo. Economía y humanismo, París, Ediciones Obreras, 1961.

Rolando Gadille: Las políticas agrarias, París, Imprentas Universitarias de Francia, 1972, Col. «One Sais-Je?», núm. 1.472.

Vicente UNZER de ALMEIDA: Entrenamiento en masa para la agricultura, São Paulo, Secretaría de la Agricultura, Asesoría de la Revisión Agraria, 1965.

República Federativa DE Brasil: II Plan Nacional de Desarrollo (1975-1979), Brasilia, 1976. 


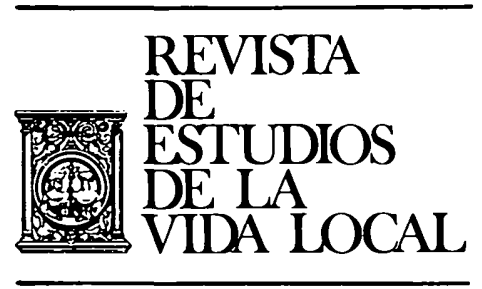

\section{ESTADISTICA}


